\title{
Enhancing the piston effect in underground railway tunnels
}

\author{
Daniel Cross*, Ben Hughes, Derek Ingham, Lin Ma \\ Energy 2050, Department of Mechanical Engineering, University of Sheffield, Sheffield S3 7NA, United Kingdom
}

\section{A R T I C L E I N F O}

\section{Article history:}

Received 7 December 2015

Received in revised form 7 September 2016 Accepted 2 October 2016

\section{Keywords:}

Underground railways

Ventilation

Piston effect

\begin{abstract}
A B S T R A C T
The air flows induced by train movement in tunnels can be used for the purposes of underground railway ventilation. The magnitude of such air flows depends strongly upon the blockage ratio (the ratio of the train and tunnel cross-sectional areas) of the train. This study investigates the impact on the generated air flows due to the alteration of the aerodynamic resistance of the train, as a means of varying the blockage ratio. The alteration in aerodynamic resistance was achieved by using an aerofoil at a variety of different angles of inclination. A two-dimensional computational fluid dynamics model of a train travelling through a tunnel was developed and validated using experimental data from literature. This model was then used to investigate the influence of an aerofoil upon the volume of displaced air and the effect upon the aerodynamic work done by the train (work done by the train due to air drag). The results of this study show that ventilating air flows can be increased by $3 \%$ using an aerofoil at a fixed angle of $10^{\circ}$ without increasing aerodynamic work. Through using a combination of different angles during different phases of train motion, a maximum increase in air displacement of $8 \%$ can be achieved, while not increasing the aerodynamic work done by the train. This equates to the train generated air displacement delivering an extra $1.6 \mathrm{~m}^{3} \mathrm{~s}^{-1}$ of air supply during the period of train motion.
\end{abstract}

(C) 2016 The Authors. Published by Elsevier Ltd. This is an open access article under the CC BY-NC-ND license (http://creativecommons.org/licenses/by-nc-nd/4.0/).

\section{Introduction}

The London Underground carries 1.305 billion passengers per year (Transport for London, 2015a) with numbers continually increasing (Transport for London, 2015b). In order to meet demand, train frequencies are being increased. This growth has placed the existing infrastructure under considerable strain. In particular, the ventilation systems which were designed for an underground network originally conceived many years ago is often unable to maintain a comfortable environment for passengers and staff. Summer temperatures in London Underground stations can regularly exceed $30^{\circ} \mathrm{C}$ (Botelle et al., 2010). Problems of this nature are found in systems around the world and with the added challenge of climate change (Jenkins et al., 2014) are expected to worsen.

Transport authorities are therefore seeking methods of improving underground railway environmental conditions. Approaches such as the upgrade of ventilation fans, installation of air conditioning on trains, construction of new ventilation shafts and the adoption of groundwater cooling systems have all been added in recent years. However, these approaches involve high construction or ongoing costs and high energy use. Additionally, the significant

\footnotetext{
* Corresponding author.

E-mail address: dcross1@sheffield.ac.uk (D. Cross).
}

nature of some of these interventions may also cause considerable disruption to normal train operations during construction.

An important mechanism for the ventilation of an underground railway is a phenomenon called the 'piston effect'. The effect is generated by a train moving through a tunnel. Since the train is confined by the tunnel walls, a pressure gradient is generated along the train and air is pushed ahead of the train and sucked from behind, thus generating an air flow. The main factors which influence the magnitude of the piston effect are the blockage ratio (defined as the ratio of the train cross-sectional area to the tunnel cross-sectional area) and the train speed, length and nose shape (Cross et al., 2015; Baron et al., 2001). The magnitude of such air flows are significant and in a newly designed underground system in a temperate climate can be sufficient for ventilation during normal operations (Bennett, 2004).

This study introduces a potential method of enhancing the piston effect, determined by the use of a validated CFD investigation. The concept is to attach aerofoils to each side of a train, i.e. between the sides of the train and the tunnel wall, in a similar manner to that of a spoiler on a car. The effect of the aerofoil is to increase the aerodynamic resistance of the train. As the air flow patterns around the train are changed, the volume of air displaced by the train will increase (Cross et al., 2015; Baron et al., 2006). Positioning the aerofoil at different angles allows the air flow patterns to be varied and therefore the volume of air displaced. A plan view of the aerofoil configuration is shown in Fig. 1. 


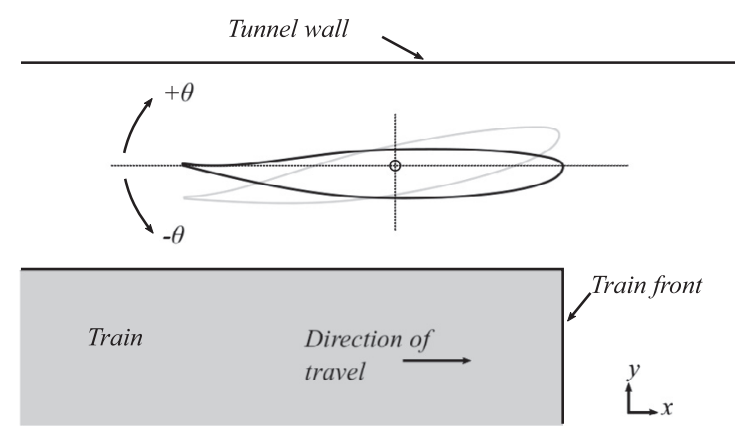

Fig. 1. Sketch of the aerofoil positioned between the side of the train and the tunnel wall.

A particular angle of inclination of the aerofoil can be determined to maximise the air displacement, minimise the aerodynamic work done by the train or as a compromise between the two parameters. A range of angles is found for increasing air displacement while not increasing aerodynamic work for different phases of train travel and a sequence of angles is given to maximise the air displacement while not increasing the aerodynamic work.

The aim of this study is to investigate the concept of using an aerofoil to alter the air flows around a train for the purposes of enhancing the piston effect. In particular, the effect on the air flows around the train are considered and the effect on the pressure and viscous drag components, as well as induced air flows. Further aspects of an aerofoil configuration will need to be considered further before application, including the size and position relative to the front and side of the train and how it may be accommodated within the constraints of a particular train-tunnel configuration. As such, the results are intended to provide insight into the effects of air aerofoil on the air flows around trains for a general traintunnel configuration, not a specific case.

\section{Previous related work}

A number of studies have considered the influence of ventilation and the piston effect upon underground railway temperatures and energy use. Ampofo et al. (2004) considered various methods of delivering cooling in a UK underground railway system and show that increasing the ventilation rate can significantly reduce the temperature in tunnels and trains. Eckford and Pope (2006) investigated increasing the ventilation rate using mechanical ventilation, train induced flows and draught relief and found that increasing the air exchange by $60 \%$, by any means, reduced the temperatures by $4{ }^{\circ} \mathrm{C}$. López González et al. (2014) carried out a numerical investigation of the airflows in a station within a network of tunnels and shafts, and found that the influence of the piston effect could give energy savings of up to $3 \%$. Yuan and You (2007) carried out an experimental and numerical investigation of the air velocity and temperature conditions on an underground station platform and optimised the ventilation to give a lower platform temperature. Ono et al. (2006) considered the operation of mechanical ventilation based on the scheduling of trains. Train induced air flows were found to be sufficient for ventilation for the majority of the day with mechanical ventilation only required at peak periods. Casals et al. (2014) presented a breakdown of the energy consumption in a Barcelona underground station. The authors found that ventilation accounted for $14 \%$ of the energy consumption but believed that this could be reduced by $30 \%$ if the train induced air flows could be better harnessed for ventilation purposes.

The influence of train geometry upon the piston effect have been considered in terms of improving ventilation and reducing undesirable pressure effects. Cross et al. (2015) considered the air flows and drag generated in high blockage ratio underground railways, finding that increasing the blockage ratio by $30 \%$ will double the air flow but also the drag on the train by the same amount. Ricco et al. (2007) investigated, numerically and experimentally, the pressure waves generated by a train passing through a tunnel. They noted that the size of a separation bubble at the train nose increases the effective blockage ratio of the train, which in turn increases pressure peaks, and is influenced by the shape of the nose. Gilbert et al. (2013) carried out an experimental study into the gusts generated by trains in tunnels, finding that they are strongly dependent on the length and the cross sectional area of the tunnel. Choi and Kim (2014) investigated increasing the nose length and cross sectional area of a tunnel to reduce the drag of a subway train with reductions of $50 \%$ found from either method.

In previous studies, the impact of the piston effect upon underground railway conditions and energy use have been investigated as well as the aerodynamics of trains in tunnels. The literature established that the piston effect benefits underground railway conditions and that the blockage ratio is a major influencing factor upon the air flows. In this work a mechanism for increasing the aerodynamic resistance for higher ventilating air flows, but which does not have a large negative effect upon the train aerodynamics, is investigated. First a benchmark numerical model is developed and validated with available experimental data. The effect of varying the blockage ratio using an aerofoil to alter the aerodynamic resistance is studied with consideration given to the air displacement and aerodynamic work done by the train. The effect of the aerofoil on the air flow behaviour and pressure and viscous forces acting upon the train is also presented.

\section{Methodology}

A transient two-dimensional (2-D) computational fluid dynamics (CFD) simulation was used to model the induced air flows generated by the train movement in a tunnel. The study consists of two parts; the validation and study of a benchmark configuration without an aerofoil and the examination of the effect of an aerofoil on the benchmark configuration.

\subsection{Benchmark configuration}

The benchmark modelling domain was a 2-D horizontal cross section of an idealised train-tunnel configuration. The model represents a train as a blunt ended rectangle positioned symmetrically between smooth tunnel walls, with the tunnel ends open to the atmosphere. The air flows around a train are 3-D in nature, in particular the air flows at the corners of a train will vary significantly from that between the corners. The 2-D model is used by assuming that the flow through the train gap does not vary significantly with the vertical position, away from the corners of the train. Moreover, the flows represented in the 2-D model are taken to represent the flows in a general train-tunnel configuration, not a specific case, and as such are considered sufficient for the purposes of this study. Additionally, a three-dimensional model of the train-tunnel configuration with an aerofoil would entail using a mesh of a prohibitively large size, given the computational resources available. The model is geometrically simple to avoid interference from other factors. Fig. 2 shows the modelling domain and characteristic lengths.

The train length $\left(T_{x}\right)$ and width $\left(T_{y}\right)$ are $50 \mathrm{~m}$ and $2.48 \mathrm{~m}$, respectively, and the tunnel length $\left(L_{x}\right)$ and width $\left(L_{y}\right)$ are $500 \mathrm{~m}$ and $2.96 \mathrm{~m}$, respectively. The width of the gap between the train side and tunnel wall, the train-tunnel gap $(L)$, is $0.24 \mathrm{~m}$ on each side, so that the train is positioned symmetrically within the tun- 


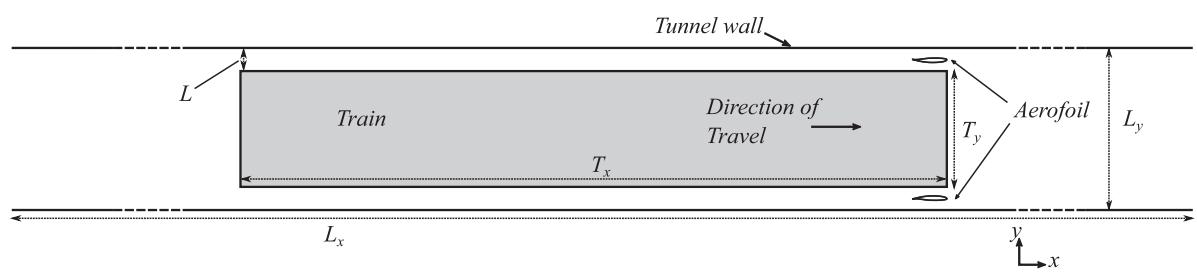

Fig. 2. Schematic diagram of the modelling domain with characteristic lengths, also showing the aerofoils used in the aerofoil configuration.

nel. The length of the train allows the air flow though the traintunnel gap to become fully developed and the tunnel length allows the transient changes in air flow behaviour to be observed. The dimensions are based on available data from the Victoria Line, London Underground, UK, a currently operating underground railway (Vardy, 1980; Transport for London, 2007).

The train is initially positioned with the rear of the train $10 \mathrm{~m}$ from the tunnel entrance portal. It is accelerated for $10 \mathrm{~s}$ at $1 \mathrm{~ms}^{-2}$, travels at a cruising speed of $10 \mathrm{~ms}^{-1}$ for $32.5 \mathrm{~s}$ then decelerates for $10 \mathrm{~s}$ at $-1 \mathrm{~ms}^{-2}$. The final position of the train is with the front of the train $15 \mathrm{~m}$ from the tunnel exit portal. The total travel time and distance are $52.5 \mathrm{~s}$ and $425 \mathrm{~m}$, respectively.

\subsection{Aerofoil configuration}

The aerofoil configuration consists of an aerofoil positioned in the train-tunnel gap in the benchmark configuration, as shown in Figs. 1 and 2. The dimensions of the train and tunnel, as well as the transient motion of the train, remain the same in the aerofoil configuration. The aerofoil chosen is the NASA LS(1)-0413 aerofoil as it has been investigated in the context of touring cars (MarquésBruna and Grimshaw, 2011) and the ground effect (Zerihan and Zhang, 2000). The aerofoil section shape is shown in Fig. 3.

The aerofoil is inverted as shown in Fig. 3, with the upper side adjacent to the tunnel wall and the lower surface adjacent to the train side. The leading point of the aerofoil is coincident with the front of the train and so that the chord line is midway between the train side and tunnel wall to ensure that the effect from either does not dominate. In practice, an attachment would be required to fix the aerofoil to the train. However, as a 2-D simulation is used in this work, any possible attachment is omitted.

The aerofoil configuration is tested with the aerofoil at a series of different angles of inclination, $\theta$. The benchmark configuration has a blockage ratio $\beta$ of 0.83 , where the blockage ratio is the ratio of the width of the train and the width of the tunnel, $\beta=T_{y} / L_{y}$. The addition of the aerofoil and variation of angle of inclination increases the blockage ratio. The chord length is chosen as $0.4 \mathrm{~m}$ so that for $\theta=0^{\circ}$ around $20 \%$ of the train-tunnel gap is blocked which increases to around $60 \%$ for $\theta=20^{\circ}$. The angles of inclination tested are shown in Table 1, along with the equivalent blockage ratios.

The aerofoil is rotated about its centroid, as shown in Fig. 3. A positive angle of inclination indicates that the trailing edge of the
Table 1

Tested angles of inclination and equivalent blockage ratios for both positive and negative inclinations.

\begin{tabular}{|c|c|c|}
\hline \multirow[t]{2}{*}{ Angle of inclination $(\theta)$} & \multicolumn{2}{|c|}{ Blockage ratio $(\beta)$} \\
\hline & $-\theta$ & $\theta$ \\
\hline $0^{\circ}$ & \multicolumn{2}{|c|}{0.87} \\
\hline $\pm 2^{\circ}$ & 0.87 & 0.87 \\
\hline $\pm 6^{\circ}$ & 0.87 & 0.87 \\
\hline $\pm 10^{\circ}$ & 0.88 & 0.89 \\
\hline $\pm 16^{\circ}$ & 0.91 & 0.92 \\
\hline $\pm 20^{\circ}$ & 0.92 & 0.93 \\
\hline
\end{tabular}

aerofoil is rotated away from the train side while a negative angle indicates the converse. The blockage ratio for each angle of inclination are very similar whether a positive or negative inclination is used.

\subsection{Mesh generation}

The numerical mesh representing the modelling domain was created in Ansys ICEM CFD. The mesh was formed in three regions; a near field region around the train and two far field regions to the front and rear of the train. The near field region was formed using a triangular cell mesh with a very high density of cells, particularly around the aerofoils. The two far field regions required a less dense mesh and a quad cell mesh was used in this case. The boundary layers are resolved by using inflation layers at the walls throughout the three regions.

The numerical modelling of the air flow was performed using the Ansys Fluent commercial CFD software package (ANSYS Inc, 2013a). The train movement was simulated using the dynamic layering option in the dynamic meshing component of Ansys Fluent, following the approach used by Huang et al. (2010). The movement of the train is achieved by the near field region moving forward at the specified train speed, defined by a user defined function (UDF), with layers of cells added to the far field region behind the near field region and removed from the region in front of the near field region. This process allowed the more complex near field region to remain unaltered with the only mesh changes occurring in the simpler far field regions. The use of dynamic layering is possible in the far field regions as they are formed of quad cell mesh (ANSYS Inc, 2013b).

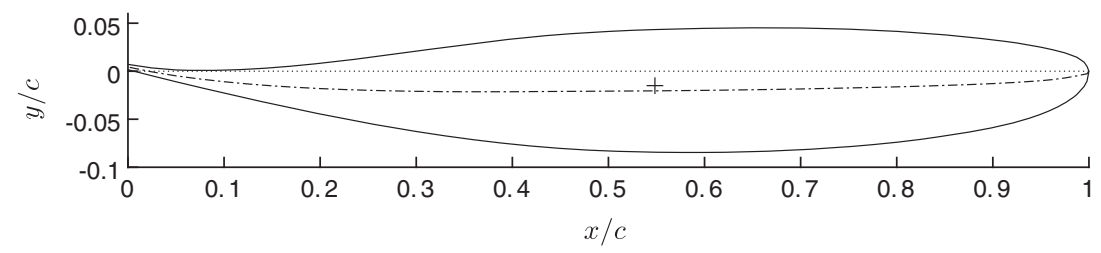

Surface -.-.-Camber ……. Chord line + Centroid

Fig. 3. Section shape of the NASA LS(1)-0413 aerofoil. 


\subsection{Numerical conditions}

For the unsteady, incompressible fluid flow in an underground railway, the Reynolds-averaged Navier Stokes equations are solved using Ansys Fluent. The $k-\epsilon$ RNG turbulence model is used in this work as it has been used previously for the investigation of train induced air flows where it performed well (Xue et al., 2014; Huang et al., 2013). Near wall modelling used the standard wall function, a wall function approach, to reduce the computational time in the transient calculations. The first cell height on the walls are chosen during mesh generation so that the non-dimensional $y^{+}$ value is maintained in the recommended range of $30 \leqslant y^{+} \leqslant 300$. The time step for the unsteady calculation is set at $0.025 \mathrm{~s}$, and this has been found to be a sufficient size through a time step independence study.

At the tunnel entry and exit portals, an outlet boundary condition of $0 \mathrm{~Pa}$ was applied. This is given relative to an operating pressure set as atmospheric pressure. This allows for the dynamic pressure to vary at the openings while the static pressure is fixed, such as when the train approaches an opening of the tunnel. This approach was used by Khayrullina et al. (2015).

Ansys Fluent uses the finite volume method on an unstructured mesh to solve the governing equations. In this work the PISO pressure-velocity coupling method is adopted to solve the governing equations, the QUICK interpolation scheme is used for the discretisation of the convection terms and the PRESTO scheme to treat the pressure interpolation. This approach was used by Huang et al. (2010). The continuity, momentum, $k$ and $\epsilon$ residual equations were monitored as the convergence criteria and set as $1 \times 10^{-5}$. Additionally, the velocity was monitored at various points within the domain as was the train drag. Mass conservation within the computational domain was also monitored to ensure conservation at every time step.

\section{Validation}

The validation of the benchmark configuration was carried out using data from the work of Gralewski (1979). This study was an investigation of the flow behaviour in the train-tunnel gap. The author used a test rig consisting of a moving and stationary wall and a fan to generate a pressure gradient to simulate the conditions in a train-tunnel gap. A series of tests were carried out with a range of wall speeds and imposed pressure gradients. The validation presented here compares five of the experimental cases with points within the transient simulation. The five validation cases are within the cruising phase of the train motion at $13.25 \mathrm{~s}, 14.25 \mathrm{~s}, 15.50 \mathrm{~s}, 17.50 \mathrm{~s}$ and $23.00 \mathrm{~s}$.

\subsection{Velocity profiles}

Fig. 4 shows velocity profiles in the train-tunnel gap for the five validation cases.

The velocity in Fig. 4 is given as $u_{a i r \mid t r} / U_{t r}$, where $u_{\text {air } \mid t r}$ is the velocity of the air relative to the train and $U_{t r}$ is the velocity of the train. The profiles are presented as a function of the nondimensional distance between the train side and tunnel wall $y / L$, where $y / L=0$ is at the train side and $y / L=1$ is at the tunnel wall. The profiles from the numerical results are measured midway between the front and back of the train. The experimental and numerical results agree well for the five cases investigated. Particularly good agreement is found towards the tunnel wall with some slight deviation near the side of the train.

The velocity profiles shown in Fig. 4 can be classified into two types; a type A which is driven by the pressure gradient along the train and opposed by the friction at the walls and a type B

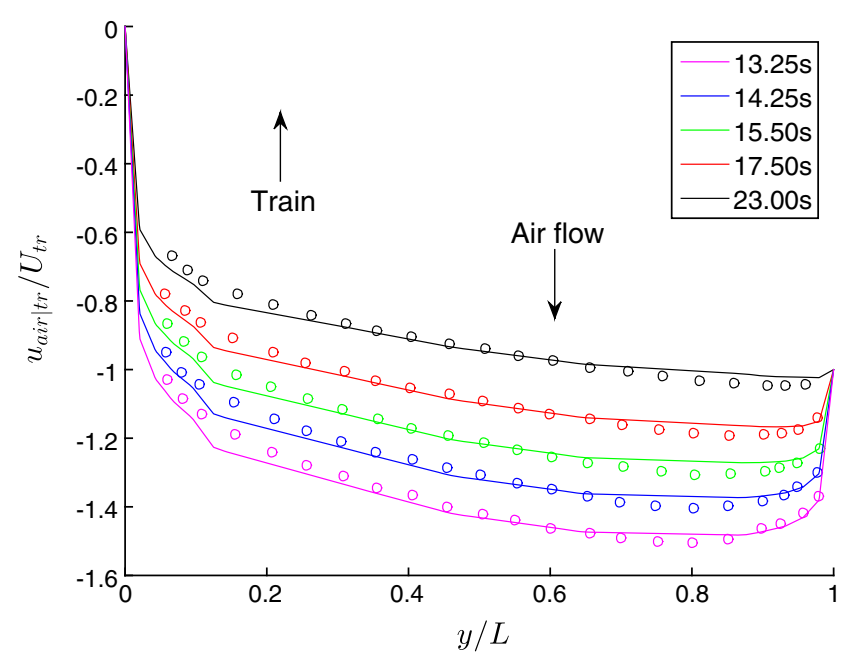

Fig. 4. Velocity profiles between the train side and tunnel wall for the five validation cases (- Numerical, o Experimental). Arrows indicate the direction of train movement and air flow relative to the train.

which is driven by the friction of the tunnel wall and it is opposed by the pressure gradient. The validation case at $t=23.00 \mathrm{~s}$ is of type $B$ while the remainder are of type A. During the acceleration phase, the pressure gradient dominates the flow within the traintunnel gap and thus forms a parabolic velocity profile (Gralewski, 1979). Once the cruising phase is entered, the velocity profile begins to flatten as the pressure gradient decreases and the friction effect at the walls begin to dominate. This leads to the profile seen for the case at $t=13.25 \mathrm{~s}$. The profiles then progressively flatten further towards the case at $t=23.00 \mathrm{~s}$, after which little further change was observed through the remaining period of the cruising phase.

\subsection{Volume flow rate and pressure gradient}

The non-dimensional volume flow rate, $\dot{V} / U_{t r} L$ where $\dot{V}$ is the volume flow rate, and the non-dimensional pressure gradient $L(d p / d x)$ where $p$ is the pressure, are shown in Fig. 5 for the five validation cases. The non-dimensional pressure gradient is measured between the front and back of the train.

The non-dimensional volume flow rate shows excellent agreement between the experimental and numerical results across all

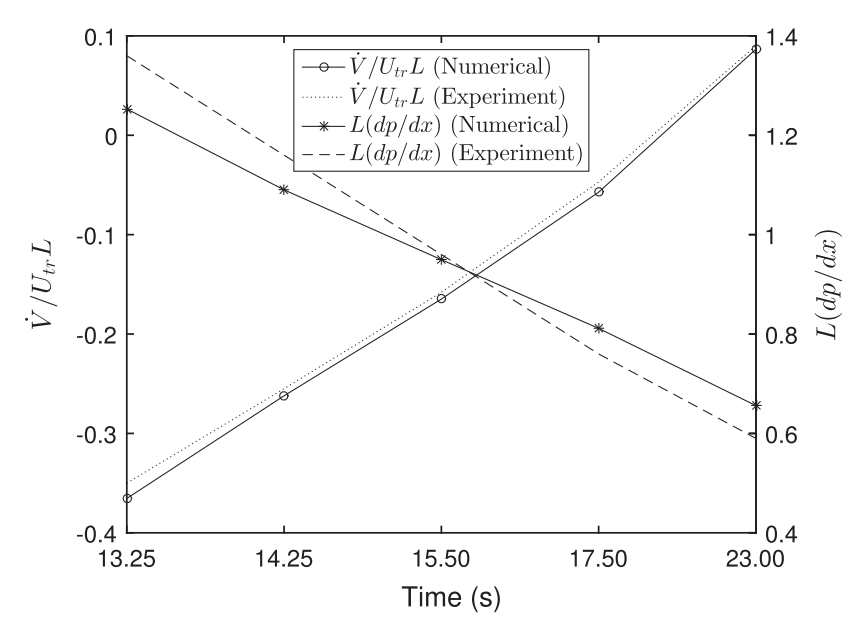

Fig. 5. Non-dimensional volume flow rate and pressure gradient as a function of time for the five validation cases. 
cases investigated, with an average error of $6.6 \%$. The nondimensional pressure gradient shows good agreement but with a larger discrepancy towards the cases at $t=13.25 \mathrm{~s}$ and at $t=23.00 \mathrm{~s}$. This is due to the numerical configuration representing the whole train rather than just the train-tunnel gap, and as such pressure losses are generated at the front and back of the train, which are not present in the experimental configuration. The average error for the non-dimensional pressure gradient is $6.5 \%$. These results illustrate the characteristics of the flow behaviour. As the time progresses, the pressure gradient decreases as the flow profile develops from type A to type B. Simultaneously, the volume flow rate relative to the train changes from negative, as expected from a type A profile, to positive as expected from type B.

\section{Results and discussion}

\subsection{Benchmark configuration}

The results from the benchmark configuration, without an attached aerofoil, were used as a benchmark for comparison with the aerofoil configuration. Transient results of the aerodynamic power and volume flow rate are shown in Fig. 6 . The dotted vertical lines indicate the end of the acceleration phase and the end of the cruising phase.

The aerodynamic power $P$ is defined as the power required by the train due to the drag force due to the air acting upon the train, and is calculated by

$P(t)=F \cdot U_{t r}$

where $F$ is the total force acting upon the train and aerofoil. The volume flow rate $\dot{V}$ was calculated at the tunnel exit portal.

During the acceleration phase of the train, the power increases steeply throughout the phase as does the volume flow rate. Once the train has stopped accelerating, the power drops sharply and tends towards a steady value towards the end of the cruising phase. During the cruising phase the volume flow rate continues to rise and tends towards a steady value near the end of the phase. During deceleration, the volume flow rate decreases as the train slows while the power increases slightly, due to the body of air behind the train continuing to move at a faster speed than the train, thus creating a force acting upon the back of the train, before decreasing once the speed of this body of air matches that of the train. The aerodynamic power is represented as a positive quantity

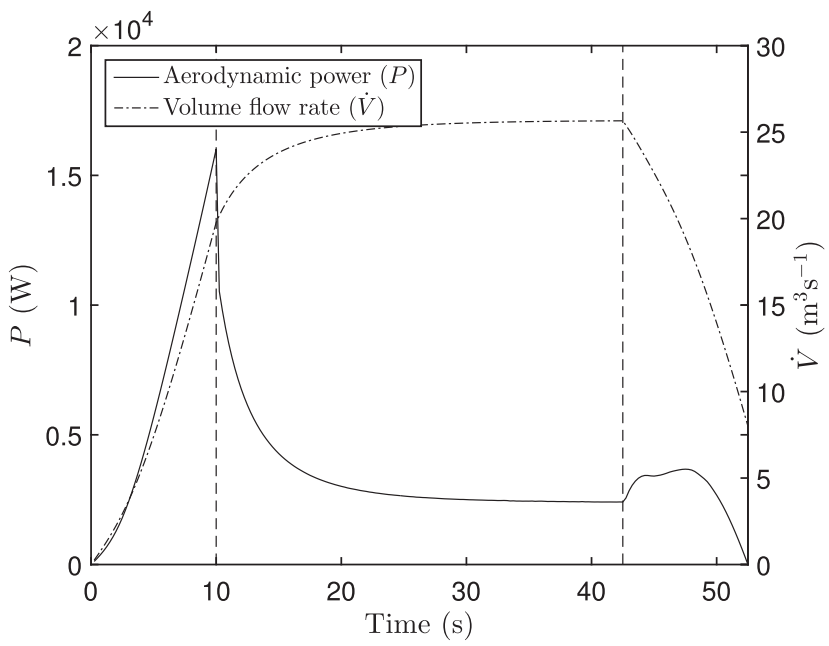

Fig. 6. Transient aerodynamic power $(P)$ and volume flow rate $(\dot{V})$ as a function of time. during deceleration as the drag force of the air is acting against deceleration, just as the drag force acts against acceleration and cruising in those phases of motion. The aerodynamic power during deceleration does not require the consumption of energy, but results in losses. Such losses are often in the form of heat, or if regenerative braking is used a certain proportion will be converted into electricity. In this work it is assumed that reducing the aerodynamic power during deceleration would be beneficial as to reduce heat dissipation.

The total volume of air displaced by the train and the total aerodynamic power, referred to as the aerodynamic work $W$, are used to compare the benchmark configuration with the aerofoil configuration cases. The total volume of air $V$ is calculated by

$V=\int_{t_{1}}^{t_{2}} \dot{V}(t) d t$

and the aerodynamic work $W$, work done by the train due to air drag, is calculated by

$W=\int_{t_{1}}^{t_{2}} P(t) d t$

where $t_{1}$ and $t_{2}$ are the start and finish times of the interval over which the quantity is calculated. In practice the train traction systems will be required to do work equivalent to the aerodynamic work, either in the form of providing traction or braking. The train requires energy in order to do work and so any changes in the aerodynamic work will directly influence the energy requirements of the train. Alternatively, during deceleration energy losses will occur, often in the form of heat.

It is found that the total air displacement due to the train and the aerodynamic work for the benchmark configuration are $1071.50 \mathrm{~m}^{3}$ and $201971.87 \mathrm{~kg} \mathrm{~m}^{2} \mathrm{~s}^{-2}$, respectively.

The air displacement and aerodynamic work occur in different proportions depending on the phase of train motion. Fig. 7 shows the proportion of the total air displacement and aerodynamic work for each phase of the train motion.

The largest proportion of air displacement and aerodynamic work occur during the cruising phase, and this is due to this being the longest phase of the motion of the train. However, the proportions of air displacement and aerodynamic work for each phase do not occur in proportion to the phase length. $32 \%$ of the aerodynamic work occurs during acceleration and 54\% during the cruising phase, while these phases account for $19 \%$ and $62 \%$ of the total time. This indicates that a large proportion of aerodynamic work occurs during the acceleration of the train. Conversely, $7 \%$ of the

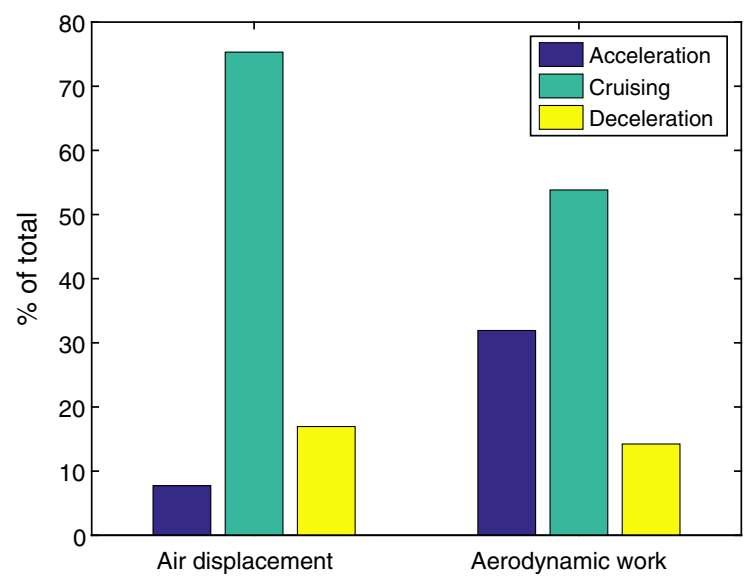

Fig. 7. Proportion of air displacement and aerodynamic work occurring in each phase of the train motion. 
air displacement occurs during the acceleration and 75\% during the cruising phase, thus showing that a larger proportion of air displacement occurs during the cruising phase.

\subsection{Air flow patterns}

The air flow around the front of the train and through the traintunnel gap is crucial in determining the behaviour of the overall flow field within the tunnel and the aerodynamic work of the train. Figs. 8-10 show the streamlines of velocity around the front of the train drawn relative to the station reference frame, coloured by $u_{\text {air } \mid r} / U_{t r}$ where $U_{t r}=10 \mathrm{~ms}^{-1}$, the normalised air velocity relative to the train. Streamlines are shown for the benchmark configuration and the aerofoil configuration for various aerofoil angles during the cruising phase at $t=20 \mathrm{~s}$.

Fig. 8(a) and (b) shows the flow behaviour for the benchmark configuration and the aerofoil configuration with $\theta=0^{\circ}$.

The main feature of the flow in the benchmark configuration is a large recirculation region within the train-tunnel gap, immediately behind the front of the train. The recirculation occupies the width of the train-tunnel gap and extends for a considerable distance through the gap. In the case of the aerofoil configuration with $\theta=0^{\circ}$ the large recirculation has been replaced by two recirculation regions, but of a smaller size. A larger region behind the aerofoil adjacent to the train side and a small secondary region just behind the train front. The streamlines between the aerofoil and tunnel wall exhibit a smooth behaviour with no recirculation.

Fig. 9(a) and (b) shows the flow behaviour for the aerofoil configuration with $\theta=6^{\circ}$ and $\theta=-6^{\circ}$.

When $\theta=6^{\circ}$ no flow recirculations occur near the front of the train and the larger region behind the aerofoil is drawn away from the side of the train due to the angle of the aerofoil. This allows the air near the side of the train to increase in velocity. When $\theta=-6^{\circ}$ the secondary recirculation near the front of the train in the $\theta=0^{\circ}$ case increases and the larger recirculation decreases in size and is moved towards the side of the train. This increases the air flow between the tunnel wall and the aerofoil.

Fig. 10(a) and (b) shows the flow for the aerofoil configuration with $\theta=16^{\circ}$ and $\theta=-16^{\circ}$.

The flow patterns for $\theta=16^{\circ}$ are similar to that seen for $\theta=6^{\circ}$ but with the recirculation moved closer to the tunnel wall and of a reduced size. For $\theta=-16^{\circ}$ both recirculation regions have reduced in size considerably compared with $\theta=-6^{\circ}$. The air above and below the aerofoil is moving towards the back of the train and the air behind the aerofoil is being dragged forward with the train.

\subsection{Pressure and viscous forces}

The changes in air flow patterns effect the forces acting upon the train due to the air acting upon the side of the train. The force

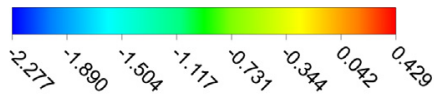
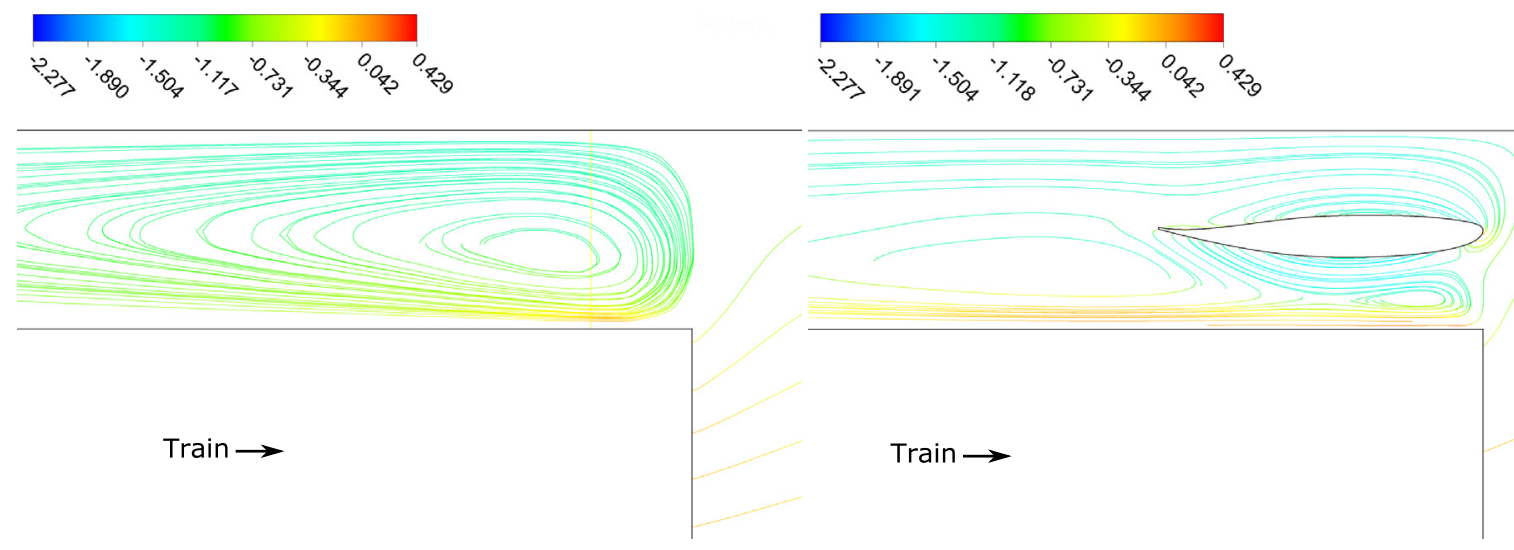

(a) Benchmark configuration.

(b) Aerofoil configuration for $\theta=0^{\circ}$.

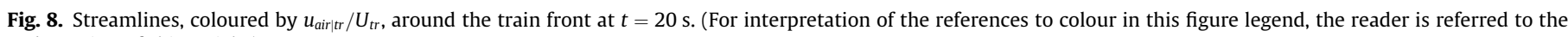
web version of this article.)

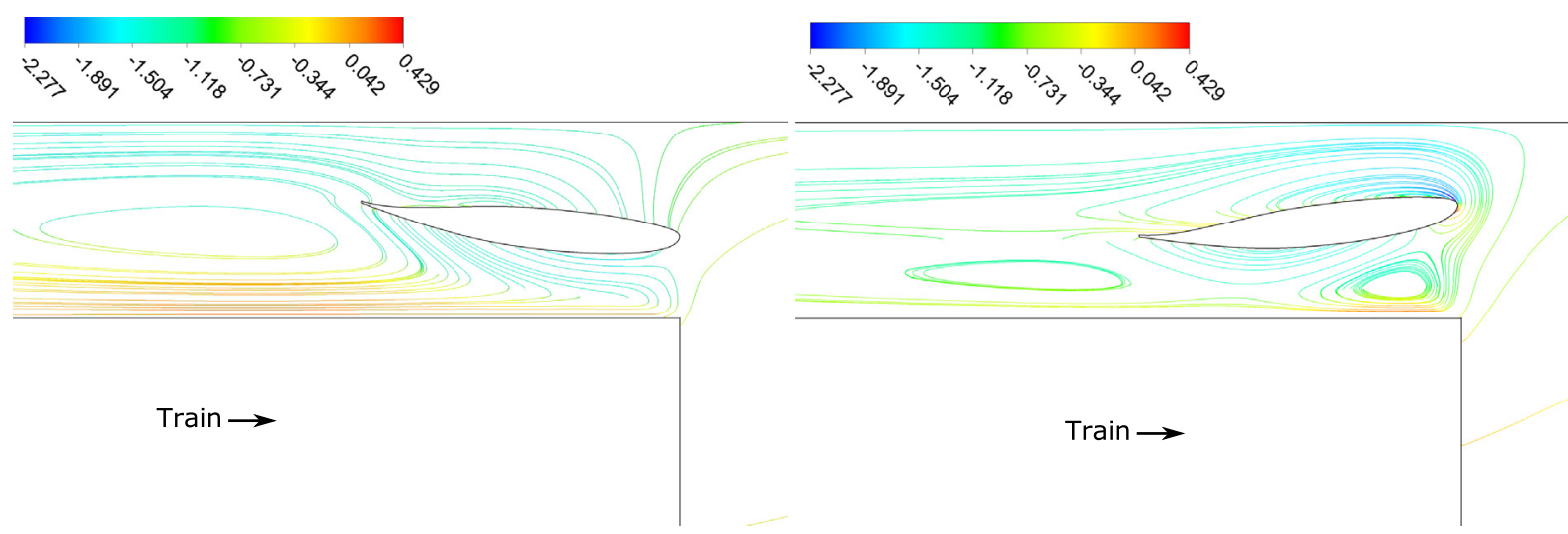

(a) Aerofoil configuration for $\theta=6^{\circ}$.

(b) Aerofoil configuration for $\theta=-6^{\circ}$.

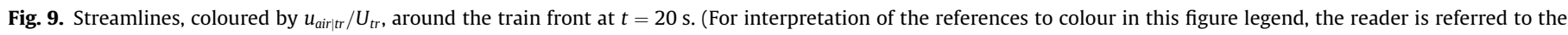
web version of this article.) 


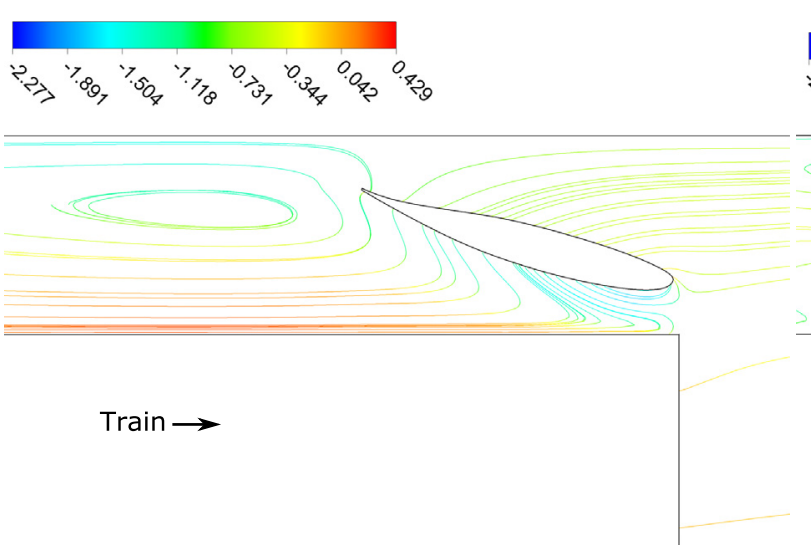

(a) Aerofoil configuration for $\theta=16^{\circ}$.
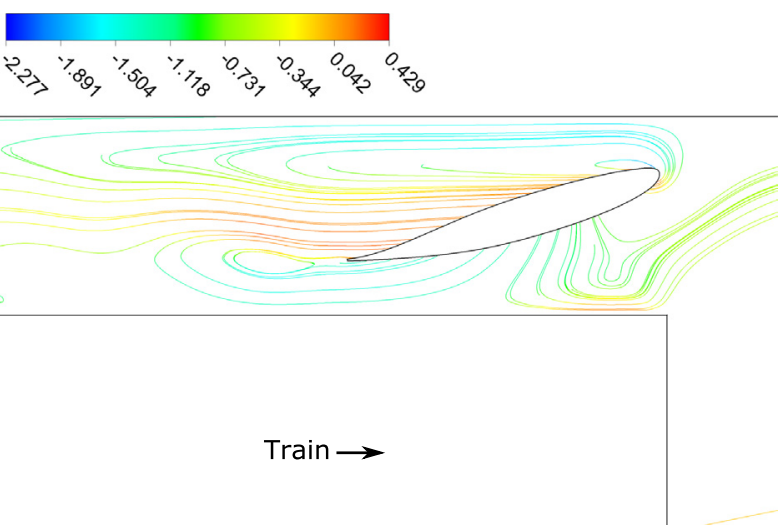

(b) Aerofoil configuration for $\theta=-16^{\circ}$.

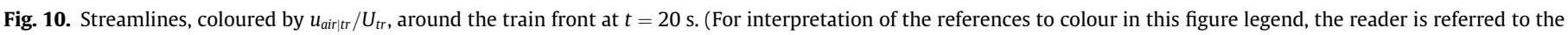
web version of this article.)

is comprised of two components; the pressure force which acts perpendicular to a surface and the viscous force acting parallel to a surface. In this case the pressure force acts upon the front and back of the train and the viscous force upon the sides of the train. The forces are presented in terms of the aerodynamic work done by the train calculated using either the pressure of viscous force in place of the total force upon the train and aerofoil in Eqs. (1) and (3), and normalised by the value from the benchmark configuration. These are referred to as the non-dimensional aerodynamic work due to the pressure force, $W_{P}^{+}$, and the non-dimensional aerodynamic work due to the viscous force, $W_{V}^{+}$.

\subsubsection{Aerodynamic work due to the pressure force}

Fig. 11 shows the non-dimensional work due to the pressure force, $W_{p}^{+}$, for the acceleration, cruising and deceleration phases, as a function of aerofoil angle. The dotted horizontal line at $W_{P}^{+}=1$ indicates the value of the benchmark configuration.

During the cruising phase, the aerofoil acts to reduce the value of $W_{P}^{+}$for all aerofoil angles. This reduction is due to the changes in the size and location of the recirculation region, shown in Figs. 8-10. A maximum reduction of $19 \%$ is achieved with an aerofoil angle of $20^{\circ}$. The reduction is lower for the corresponding negative angle of $-20^{\circ}$ due to the creation of the secondary recirculation region near the front of the train. During the acceleration phase, the aerofoil reduces $W_{P}^{+}$for the angles $-10^{\circ} \leqslant \theta \leqslant 6^{\circ}$. The

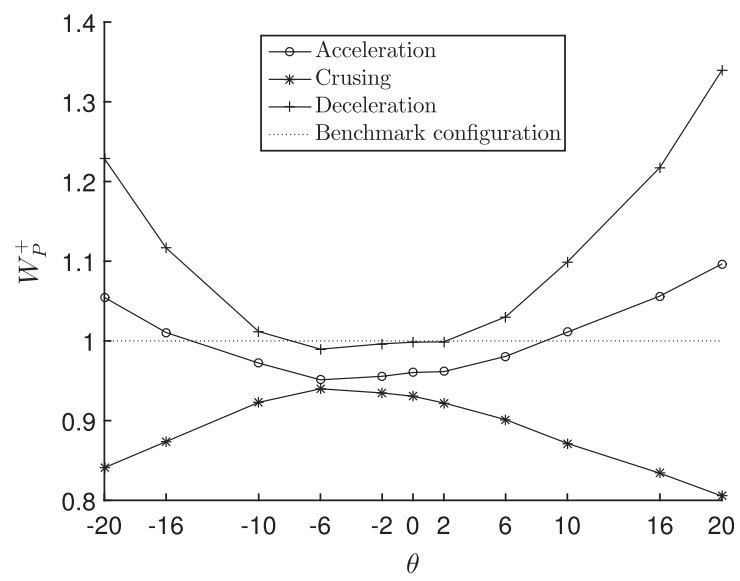

Fig. 11. Normalised aerodynamic work due to the pressure force, $W_{P}^{+}$as a function of the aerofoil angle $\theta$. reduction during this phase is less significant and over a smaller range of angles since there is not a significant recirculation at the front of the train in the benchmark configuration and that the train is overcoming the inertia of the air. Additionally the aerofoil acts to create a recirculation region when positioned at higher positive and negative angles of inclination. During the deceleration phase, the effect of the aerofoil is to generally increase the value of $W_{P}^{+}$. In this case, it is the effect of the body of air moving from behind the train and acting upon the back region of the train as it slows which creates the increase in the value of $W_{p}^{+}$. At higher angles of $\theta$, a greater air flow is induced in the tunnel during the acceleration and cruising phases of train motion and so leads to a greater force acting upon the train during deceleration.

\subsubsection{Aerodynamic work due to the viscous force}

Fig. 12 shows the non-dimensional aerodynamic work due to the viscous force, $W_{V}^{+}$, for the acceleration, cruising and deceleration phases, as a function of the aerofoil angle. The dotted horizontal line at $W_{V}^{+}=1$ indicates the value of the benchmark configuration.

Generally the effect of the aerofoil is a reduction in $W_{V}^{+}$for all phases of the train motion and most aerofoil angles. During the acceleration and cruising phases, this is due to the aerofoil directing the air flow away from the sides of the train and the aerofoil

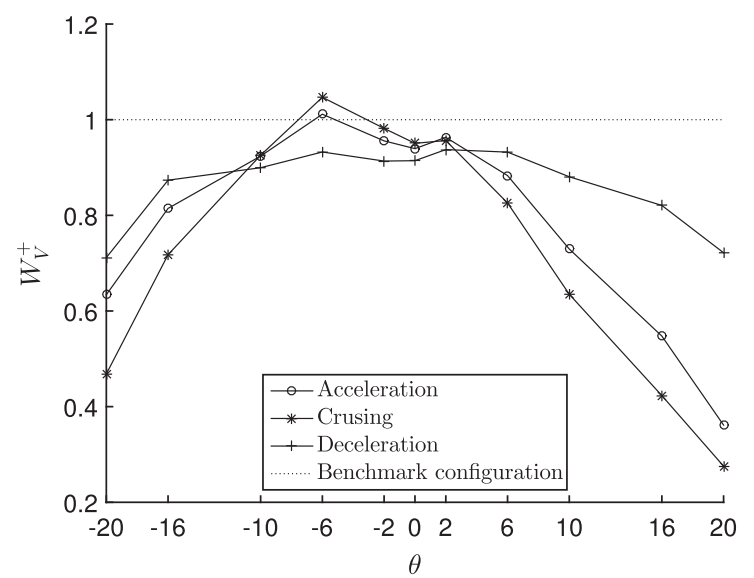

Fig. 12. Normalised aerodynamic work due to the viscous force, $W_{V}^{+}$as a function of the aerofoil angle $\theta$. 
reducing the flow of air through the train-tunnel gap. At $\theta=-6^{\circ}$, the aerofoil increases the air flow through the train-tunnel gap, thus increasing $W_{V}^{+}$. During deceleration, the reduction is due to the increase in air flow through the train-tunnel gap from the back to the front of the train, so the velocity is relatively closer to that of the train wall velocity for a larger proportion of this phase.

\subsection{Air displacement and aerodynamic work}

The displaced air volume and total aerodynamic work done by the train and aerofoil are calculated using Eqs. (1)-(3) and normalised by dividing the result by the value from the benchmark configuration. These are referred to as the normalised air displacement $V^{+}$and aerodynamic work $W^{+}$. The air displacement and total aerodynamic work are given for the total time of train travel and separately for the three phases of the train motion.

\subsubsection{Total travel time}

Fig. 13 shows the normalised displaced air volume and aerodynamic work done by the train for the total travel time for various aerofoil angles. The dotted horizontal line at $W^{+}, V^{+}=1$ indicates the value of the benchmark configuration.

The air displacement is greater for angles $6^{\circ} \leqslant \theta \leqslant 20^{\circ}$ and for $-16^{\circ}$ and $-20^{\circ}$ than the value of the benchmark configuration. The aerodynamic work is lower than the benchmark configuration for aerofoil angles $-10^{\circ} \leqslant \theta \leqslant 10^{\circ}$. Therefore an increase in displaced air is achieved without increasing aerodynamic work for aerofoil angles of $6^{\circ}$ and $10^{\circ}$. An angle of $6^{\circ}$ increases the air displacement by $2.4 \%$ and a $10^{\circ}$ angle by 3.0\%. A maximum increase in air displacement is found to be $5.5 \%$ for an angle of $20^{\circ}$ but this also increases the aerodynamic work by a similar proportion.

The air displacement can be increased without also increasing the aerodynamic work done by the train. This is due to the reduction in work done by the train due to the pressure and viscous forces as a consequence of the changes in flow pattern induced by the aerofoil. The reduction of these forces counteract the increase in aerodynamic work due to the aerofoil displacing a larger air volume.

The increase in air displacement is lower for a negative aerofoil inclination than for the corresponding positive aerofoil angle. This is due to the creation of a recirculation region at the front of the train for negatively inclined aerofoil angles, as shown in Figs. 8-10, and an increase in air flow over the top of the

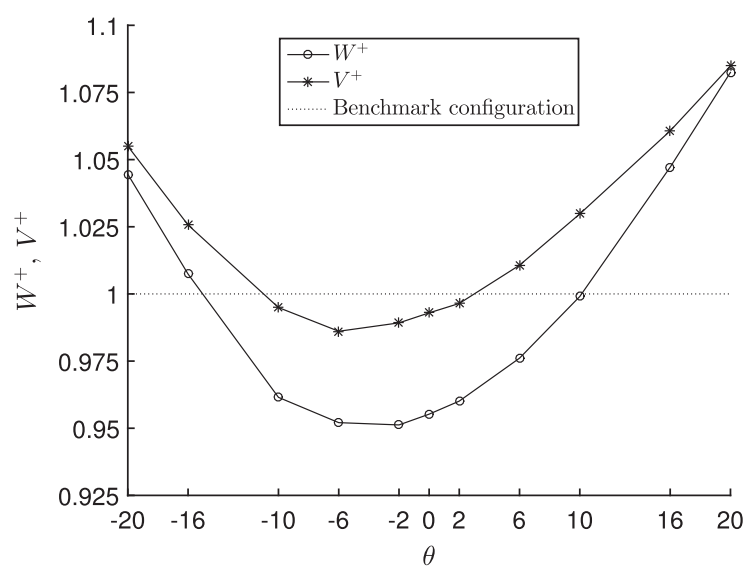

Fig. 13. Normalised displaced air volume $\left(V^{+}\right)$and aerodynamic work $\left(W^{+}\right)$over the total time as a function of aerofoil angle $\theta$.

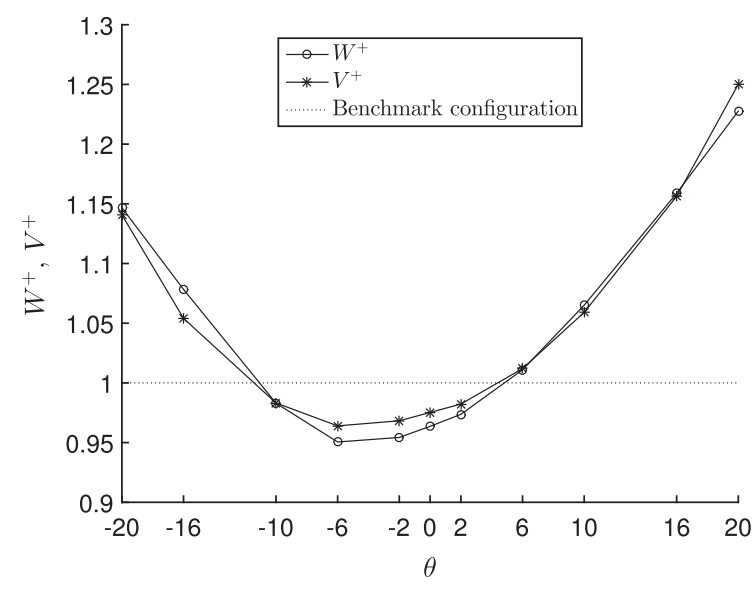

Fig. 14. Normalised displaced air volume $\left(V^{+}\right)$and aerodynamic work $\left(W^{+}\right)$during the acceleration phase as a function of aerofoil angle $\theta$.

aerofoil. This encourages greater air flow through the traintunnel gap from the front of the train to the back and in turn this reduces the volume of air displaced by the train through the tunnel exit portal.

\subsubsection{Acceleration phase}

Fig. 14 shows the normalised displaced air volume and aerodynamic work for the acceleration phase for various aerofoil angles of inclination.

The displaced air volume and aerodynamic work vary in a similar manner during the acceleration phase. Aerofoil angles $-10^{\circ} \leqslant \theta \leqslant 2^{\circ}$ decreases the aerodynamic work and air displacement while aerofoil angles $6^{\circ} \leqslant \theta \leqslant 20^{\circ},-16^{\circ}$ and $20^{\circ}$ increases the aerodynamic work and air displacement. Thus no increase in air displacement is possible without also increasing the aerodynamic work.

\subsubsection{Cruising phase}

Fig. 15 shows the normalised displaced air volume and aerodynamic work done by the train for the cruising phase for various aerofoil angles of inclination.

Except for the angles $-10^{\circ} \leqslant \theta \leqslant 2^{\circ}$, air displacement increases during the cruising phase of motion. A maximum increase of $9.1 \%$ is given for an aerofoil angle of $20^{\circ}$. For the decrease in displacement observed for $-10^{\circ} \leqslant \theta \leqslant 2^{\circ}$, the decrease is by a maximum of $1.4 \%$. For all aerofoil angles a

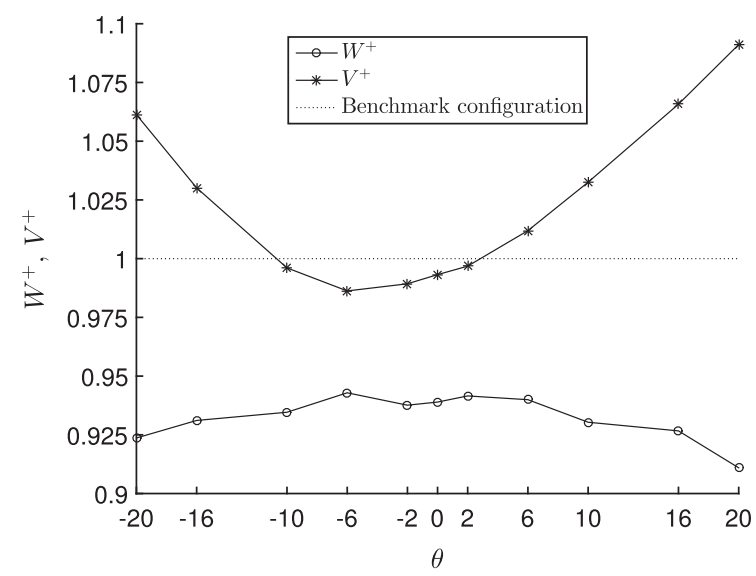

Fig. 15. Normalised displaced air volume $\left(V^{+}\right)$and aerodynamic work $\left(W^{+}\right)$during the cruising phase as a function of aerofoil angle $\theta$. 
significant reduction in work is observed with a maximum reduction of $8.9 \%$ for an angle of $20^{\circ}$.

\subsubsection{Deceleration phase}

Fig. 16 shows the normalised displaced air volume and aerodynamic work for the deceleration phase for various aerofoil angles of inclination.

The displaced air shows little variation with aerofoil angle, changing by less than $1 \%$ for $-16^{\circ} \leqslant \theta \leqslant 16^{\circ}$ with increases in air displacement observed for $0 \leqslant \theta \leqslant 6^{\circ}$. A maximum decreases in air displacement of $1.8 \%$ and $1.2 \%$ are found for angles of inclination of $-20^{\circ}$ and $20^{\circ}$, respectively. The aerodynamic work increases significantly for $10^{\circ} \leqslant \theta \leqslant 20^{\circ},-20^{\circ}$ and $-16^{\circ}$ with a maximum increase of $40 \%$.

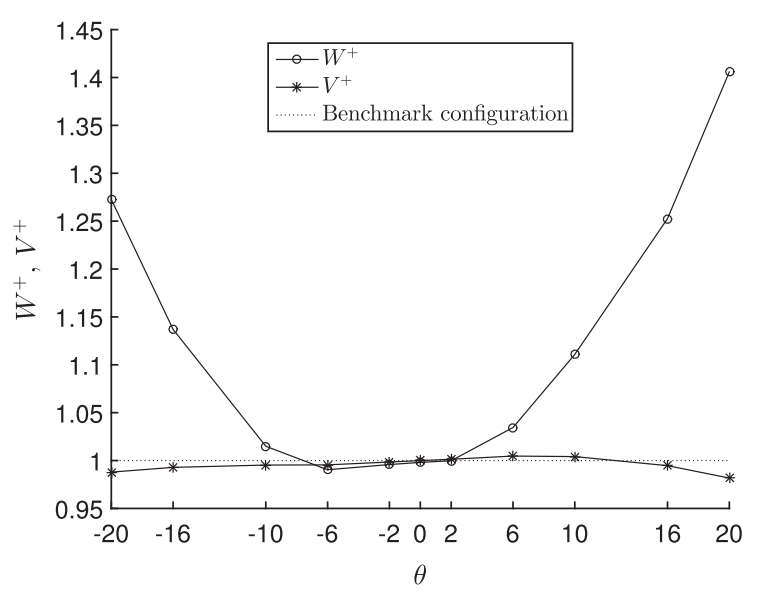

Fig. 16. Normalised displaced air volume $\left(V^{+}\right)$and aerodynamic work $\left(W^{+}\right)$during the deceleration phase as a function of aerofoil angle $\theta$.

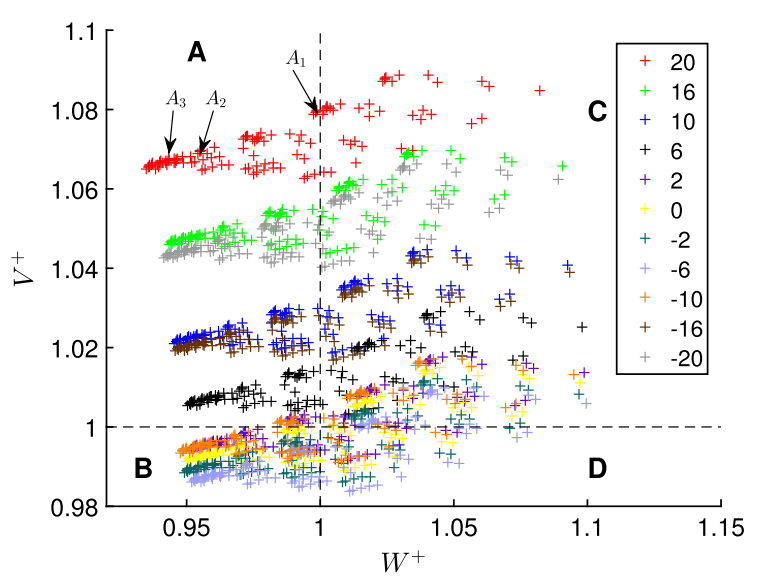

Fig. 17. All possible aerofoil combinations, coloured by inclination angle $\theta$ during the cruising phase. (For interpretation of the references to colour in this figure legend, the reader is referred to the web version of this article.)

\subsection{Aerofoil combinations}

The angle of the aerofoil selected results in different increases or decreases in air displacement and aerodynamic work depending on the phase of motion of the train. Therefore, instead of using a fixed angle throughout train travel a selection of different angles during each phase could be used to achieve a particular level of performance. In this work, 11 aerofoil angles have been tested which means that it is possible to analyse the performance of 1331 different combinations. To calculate the performance of all possible combinations the air displacement and aerodynamic work from each phase are totalled for all the possible aerofoil combinations. This does not take account for the transition from one angle to another, for instance it does not consider the effect of a particular angle upon another phase of motion, but is considered sufficient for the purposes of illustrating the possible performance in terms of displaced air and aerodynamic work of different aerofoil combinations. Fig. 17 shows the non-dimensionalised air displacement and aerodynamic work for all 1331 possible aerofoil combinations. The points are coloured by the aerofoil angle during the cruising phase, as it is during this phase that the majority of air is displaced and aerodynamic work is done.

The dashed lines in Fig. 17 indicate the displaced air volume and aerodynamic work from the benchmark configuration. The dashed lines create four regions, labelled A, B, C and D. Points in regions A, $B, C$ and $D$ represent aerofoil combinations which reduce aerodynamic work and increase air displacement, reduce aerodynamic work and reduce air displacement, increase aerodynamic work and increase air displacement and increase aerodynamic work and decrease air displacement, respectively.

From a visual examination, an aerofoil angle of $20^{\circ}$ during the cruising phase produces an increase in displaced air of between $6 \%$ and $8 \%$ without any increase in aerodynamic work. An aerofoil angle of $16^{\circ}$ or $-20^{\circ}$ may increase the displaced air by between $5 \%$ and $6 \%, 10^{\circ}$ or $-16^{\circ}$ by between $2 \%$ and $3 \%$ and $6^{\circ}$ by $1 \%$, with the reduction in aerodynamic work ranging from negligible to about $6.5 \%$. The other angles of inclination generally do not increase the overall air displacement. Three examples of aerofoil angle combinations are given in Table 2 with the resulting non-dimensional air displacement and aerodynamic work.

Case $A_{1}$ is a combination of aerofoil angles which gives maximum air displacement while not increasing aerodynamic work. The displaced air is increased by $8 \%$ with aerodynamic work reduced but a negligible amount. Case $A_{2}$ gives a increase in air displacement of $7 \%$ and a reduction in aerodynamic work of $4.5 \%$. Case $A_{3}$ gives the same increase in air displacement as case $A_{2}, 7 \%$, but a greater reduction in aerodynamic work of $5.5 \%$. The increase in the air displacement is equivalent to an increase in the air supply rate during the train motion of $1.6 \mathrm{~m}^{3} \mathrm{~s}^{-1}$ for case $A_{1}$ and $1.3 \mathrm{~m}^{3} \mathrm{~s}^{-1}$ for cases $A_{2}$ and $A_{3}$.

The aerodynamic work is lower for case $A_{3}$ than case $A_{2}$, however the air displacement is the same for both cases. This is due to the lower angle of inclination used during the acceleration phase for case $A_{3}$ which reduces the air displacement negligibly and aerodynamic work significantly, since a small proportion of air displacement and a large proportion of aerodynamic work occur during acceleration, as shown in Fig. 7.

Table 2

Selected examples of aerofoil combinations.

\begin{tabular}{|c|c|c|c|c|c|}
\hline \multirow[t]{2}{*}{ Case } & \multicolumn{3}{|c|}{ Aerofoil angle } & \multirow[t]{2}{*}{$W^{+}$} & \multirow[t]{2}{*}{$V^{+}$} \\
\hline & Acceleration & Cruising & Deceleration & & \\
\hline$A_{1}$ & -20 & 20 & 2 & 0.9988 & 1.0798 \\
\hline$A_{2}$ & 6 & 20 & 2 & 0.9554 & 1.0698 \\
\hline$A_{3}$ & 2 & 20 & 2 & 0.9435 & 1.0698 \\
\hline
\end{tabular}




\section{Conclusion}

This study evaluated the effect of having an aerofoil placed on the sides of a train by investigating the train generated air displacement and aerodynamic work done by the train. A 2-D computational model was validated with experimental data for a train running through a tunnel and a series of test cases were performed with the aerofoil at a variety of angles of inclination.

An aerofoil at a fixed angle of $10^{\circ}$ throughout the motion of the train was found to increase air displacement by 3\% while not increasing the aerodynamic work done by the train. The increase in air displacement without increasing aerodynamic work done by the train is possible due to the changes in flows patterns induced by the aerofoil and thus the forces acting upon the train.

It was shown that by using different aerofoil angles in the three phases of the train motion, further increases in air displacement are possible without increasing aerodynamic work. This is possible due to the uneven distribution of the air displacement and aerodynamic work within the three phases of train motion, so a high angle may be used during cruising where air displacement is high, but during acceleration, a lower angle of inclination may be used as the air displacement within this phase is much less significant. It was found that an increase in air displacement of $8 \%$ could be achieved along with no increase in aerodynamic work.

This study shows that increasing the blockage ratio using an aerofoil can increase the ventilating air flows while not increasing aerodynamic work. While this has been illustrated in a 2-D study, further work is required to understand how this may behave in a three-dimensional situation. Consideration could also be given to the detailed design of the aerofoil and it's operation as well as the possibility of using multiple aerofoils at different locations upon the train.

In practice, most trains currently in operation will have some form of aerodynamic shaping, rather than the blunt shape used in this study. Therefore, the effect of an aerofoil on a contemporary train may vary from the results shown in this study. However, as Ricco et al. (2007) have shown, flow separation occurs even with fairly streamlined shapes, so the effect of an aerofoil may still be beneficial in terms of reducing aerodynamic work and increasing air flow. In particular, using an aerofoil with on a streamlined train may be relatively more effective at increasing air flow and less effective and reducing aerodynamic work.

The performance of a aerofoil will also vary in lower blockage ratio train-tunnel configurations and where the train runs above ground. In these situations the relative proportions of the pressure and viscous drag components will change, with the viscous drag becoming more dominant Vardy (1996). However, in the case of lower blockage ratios, significant pressure will still be generated ahead of the train and areas of flow recirculation will still exist Ricco et al. (2007). While running above ground, it may be possible to determine an aerofoil angle which is optimal for this scenario.

\section{Acknowledgements}

The authors would like to thank BCC Consulting and the UK Engineering and Physical Sciences Research Council (EPSRC) for supporting this work through an Industrial CASE Award (Grant No. 1344073).

\section{References}

Ampofo, F., Maidment, G., Missenden, J., 2004. Underground railway environment in the UK: part 3: methods of delivering cooling. Appl. Therm. Eng. 24, 647-659. http://dx.doi.org/10.1016/j.applthermaleng.2003.10.019 <http:// www.sciencedirect.com/science/article/pii/S1359431103003387>.
ANSYS Inc, 2013a. ANSYS Fluent. 15th ed., Canonsbury, PA.

ANSYS Inc, 2013b. ANSYS Fluent Theory Guide. 15th ed., Canonsbury, PA.

Baron, A., Molteni, P., Vigevano, L., 2006. High-speed trains: prediction of micropressure wave radiation from tunnel portals. J. Sound Vib. 296, 59-72. http://dx. doi.org/10.1016/j.jsv.2006.01.067 <http://www.sciencedirect.com/science/ article/pii/S0022460X06002185>.

Baron, A., Mossi, M., Sibilla, S., 2001. The alleviation of the aerodynamic drag and wave effects of high-speed trains in very long tunnels. J. Wind Eng. Ind. Aerodynam. 89, 365-401. http://dx.doi.org/10.1016/S0167-6105 (00)00071-4 <http://www.sciencedirect.com/science/article/pii/S01676105 $00000714>$.

Bennett, D., 2004. Architecture of the Day Line Extension. Thomas Telford, London.

Botelle, M., Payne, K., Redhead, B., 2010. Squeezing the heat out of London's Tube. In: Proceedings of the Institution of Civil Engineers - Civil Engineering <http:// www.icevirtuallibrary.com/doi/full/10.1680/cien.2010.163.3.114>.

Casals, M., Gangolells, M., Forcada, N., Macarulla, M., Giretti, A., 2014. A breakdown of energy consumption in an underground station. Energy Build. 78, 89-97. http://dx.doi.org/10.1016/j.enbuild.2014.04.020 www.sciencedirect.com/science/article/pii/S0378778814003284>.

Choi, J.K., Kim, K.H., 2014. Effects of nose shape and tunnel cross-sectional area on aerodynamic drag of train traveling in tunnels. Tunnell. Undergr. Space Technol. 41, 62-73. http://dx.doi.org/10.1016/j.tust.2013.11.012 <http:// www.sciencedirect.com/science/article/pii/S088677981300196X>.

Cross, D., Hughes, B., Ingham, D., Ma, L., 2015. A validated numerical investigation of the effects of high blockage ratio and train and tunnel length upon underground railway aerodynamics. J. Wind Eng. Ind. Aerodynam. 146, 195-206. http://dx. doi.org/10.1016/j.jweia.2015.09.004 <http://www.sciencedirect.com/science/ article/pii/S0167610515002202>.

Eckford, D.C., Pope, C.W., 2006. Cooling of underground railways. Int. Symp. Aerodynam. Ventil. Vehic. Tunn. 1, 409-424.

Gilbert, T., Baker, C., Quinn, A., 2013. Aerodynamic pressures around high-speed trains: the transition from unconfined to enclosed spaces. Proc. Inst. Mech. Eng. Part F: J. Rail Rapid Transit 227, 609-622. http://dx.doi.org/10.1177/ 0954409713494947.

Gralewski, Z.A., 1979. The Aerodynamic Drag of Tube Vehicles Travelling At Subsonic Speeds. Loughborough University https://dspace.lboro.ac.uk/dspacejspui/handle/2134/7921.

Huang, Y.D., Gao, W., Kim, C.N., 2010. A numerical study of the train-induced unsteady airflow in a subway tunnel with natural ventilation ducts using the dynamic layering method. J. Hydrodynam., Ser. B 22, 164-172. http:/dx.doi. org/10.1016/S1001-6058(09)60042-1 <http://www.sciencedirect.com/science/ article/pii/S1001605809600421>.

Huang, Y.D., Gong, X.L., Peng, Y.J., Kim, C.N., 2013. Effects of the solid curtains on natural ventilation performance in a subway tunnel. Tunnell. Undergr. Space Technol. 38, 526-533. http://dx.doi.org/10.1016/j.tust.2013.08.009 <http:// www.sciencedirect.com/science/article/pii/S0886779813001296>.

Jenkins, K., Gilbey, M., Hall, J., Glenis, V., Kilsby, C., 2014. Implications of climate change for thermal discomfort on underground railways. Transport. Res. Part D: Transp. Environ. 30, 1-9. http://dx.doi.org/10.1016/j.trd.2014.05.002 <http:// www.sciencedirect.com/science/article/pii/S1361920914000285>.

Khayrullina, A., Blocken, B., Janssen, W., Straathof, J., 2015. CFD simulation of train aerodynamics: train-induced wind conditions at an underground railroad passenger platform. J. Wind Eng. Ind. Aerodynam. 139, 100-110. http://dx.doi. org/10.1016/j.jweia.2015.01.019 <http://www.sciencedirect.com/science article/pii/S0167610515000288>.

López González, M., Galdo Vega, M., Fernández Oro, J.M., Blanco Marigorta, E., 2014 Numerical modeling of the piston effect in longitudinal ventilation systems for subway tunnels. Tunnell. Undergr. Space Technol. 40, 22-37. http://dx.doi.org 10.1016/j.tust.2013.09.008 <http://www.sciencedirect.com/science/article/pii/ S0886779813001387>.

Marqués-Bruna, P., Grimshaw, P., 2011. Design of the Grand Touring sports car wing. Proc. Inst. Mech. Eng., Part P: J. Sports Eng. Technol. 225, 22-31. http://dx. doi.org/10.1177/17543371JSET79 <http://pip.sagepub.com/content/225/1/22 abstract>.

Ono, T., Iwai, K., Maeda, K., 2006. A new air conditioning and ventilation scheduling method for subway energy saving utilizing the wind driven by trains. Int. Symp. Aerodynam. Ventil. Vehic. Tunn. 1, 437-450.

Ricco, P., Baron, A., Molteni, P., 2007. Nature of pressure waves induced by a high-speed train travelling through a tunnel. J. Wind Eng. Ind. Aerodynam. 95 781-808. http://dx.doi.org/10.1016/j.jweia.2007.01.008 <http://www. sciencedirect.com/science/article/pii/S0167610507000189>.

Transport for London, 2007. Rolling Stock Information Sheets. Technical Report Transport for London.

Transport for London, 2015a. Facts \& Figures - Transport for London. <https:// tfl.gov.uk/corporate/about-tfl/what-we-do/london-underground/facts-andfigures>.

Transport for London, 2015b. London Underground Performance report. Technical Report. Transport for London. <http://content.tfl.gov.uk/lu-performance-reportperiod-6-2015-16.pdf>.

Vardy, A.E., 1980. Unsteady airflows in rapid transit systems part 1: measurements on the London transport victoria line. ARCHIVE: Proc. Inst Mech. Eng. 1847-1982 (vols 1-196) 194, 341-348. http://dx.doi.org/10.1243/ PIME_PROC_1980_194_040_02 <http://pme.sagepub.com/content/194/1/341. short>.

Vardy, A.E., 1996. Aerodynamic drag on trains in tunnels part 2: prediction and validation. ARCHIVE: Proc. Inst. Mech. Eng., Part F: J. Rail Rapid Transit 
1989-1996 (vols 203-210) 210, 39-49. http://dx.doi.org/10.1243/ PIME_PROC_1996_210_325_02 <http://pif.sagepub.com/content/210/1/39. short>.

Xue, P., You, S., Chao, J., Ye, T., 2014. Numerical investigation of unsteady airflow in subway influenced by piston effect based on dynamic mesh. Tunnel. Undergr. Space Technol. 40, 174-181. http://dx.doi.org/10.1016/j.tust.2013.10.004 <http://www.sciencedirect.com/science/article/pii/S0886779813001600>.
Yuan, F.D., You, S.J., 2007. CFD simulation and optimization of the ventilation for subway side-platform. Tunnell. Undergr. Space Technol. 22, 474-482. http://dx. doi.org/10.1016/j.tust.2006.10.004 <http://www.sciencedirect.com/science/ article/pii/S0886779806001167>.

Zerihan, J., Zhang, X., 2000. Aerodynamics of a single element wing in ground effect. J. Aircraft 37, 1058-1064. http://dx.doi.org/10.2514/2.2711 <http://arc.aiaa. org/doi/abs/10.2514/2.2711 ?journalCode=ja>. 